\title{
Crystallization and Polymorphism-Scalable Process for Celecoxib and It's Polymorph From-3 (Non- Steroidal Anti-Inflammatory Drug (NSAID)
}

\author{
Krishnasarma Pathy* and MS Chakravarthy \\ Research Centre Lucknow, India
}

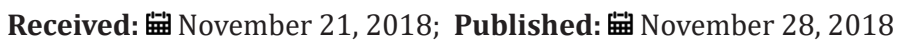

*Corresponding author: Krishna Sarma Pathy, Head -QC, QA/R\&D-IPL Research Centre Lucknow, India

\begin{abstract}
The present process provides an improved process for the preparation of 4-[5-(4-methylphenyl)-3- (trifluoromethyl)-1Hpyrazol-1-yl] benzene sulfonamide (Celecoxib) and its purification and crystallization to produce polymorph. The present process, which describes the manufacturing process of Celecoxib, which is a non- steroidal anti-inflammatory drug (NSAID), has the advantage of scaling up to the industrial level of production. The process uses safe reagents in the process which makes it for industrial scale operations. The yields in the process are high, which makes it a cost-effective process. Formation of isomers are less compared with the all existing process, which makes it effective to make it to the pharmacopoeia grade. Residual solvents play a very important role in the impurity profile of APIs as per the ICH Guidelines ICH Q3C (R4). In this process by carrying out the final step of condensation in the aqueous medium followed by crystallization, the residual solvents limits are well taken care of.

Keywords: Non-steroidal anti-inflammatory drug (NSAID); Celecoxib; Cyclooxygenase 2; X-ray diffraction; Polymorphism; Process
\end{abstract}

\section{Discussion}

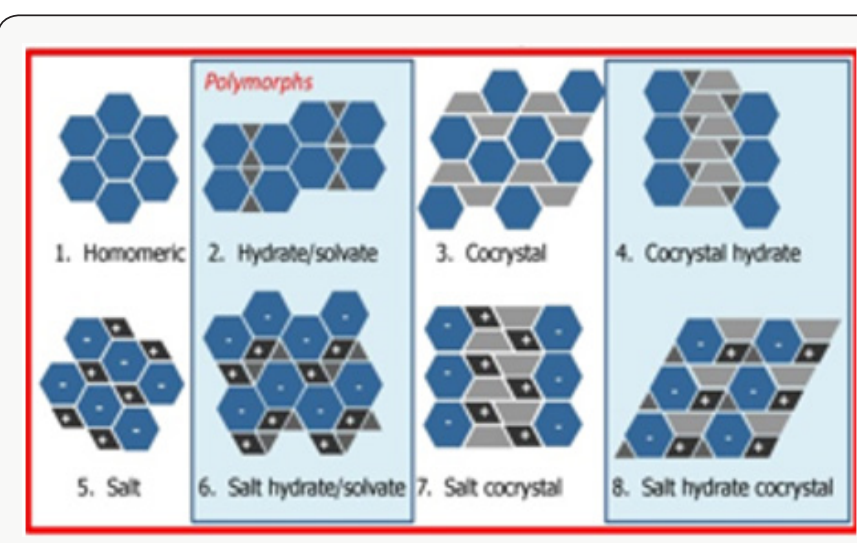

Figure 1: Classes of multi component molecular crystals.

Figure 1 present process relates to "AN IMPROVED PROCESS FOR THE PREPARATION OF CELECOXIB POLYMORPH FORM". Celecoxib is designated chemically as 4-[5-(4-methylphenyl)-3(trifluoromethyl)- 1H-pyrazol-1-yl] benzene sulphonamide and is a diaryl-substituted pyrazole [1]. The compound has the following structure (Figure 2).

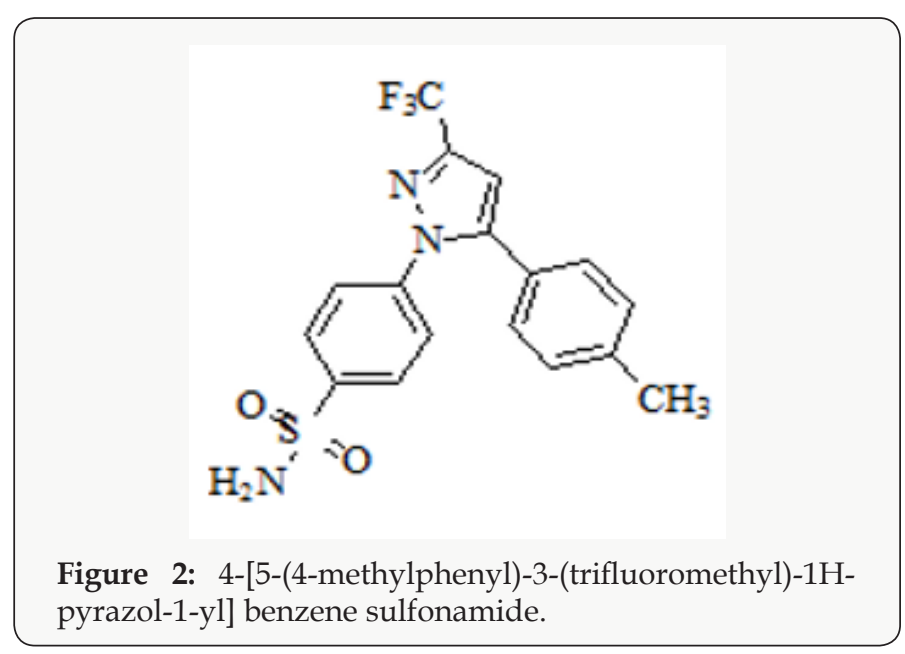

The drug is currently marketed as Celebrex $₫$ in the United States of America by Pharmacia Corporation. Celecoxib is a non-steroidal anti-inflammatory drug (NSAID) [1] mainly used in treatment of arthritis, pain, menstrual cramps, and colonic polyps. Celecoxib blocks the enzyme (cyclooxygenase 2) which 
makes prostaglandins, resulting in lowering the concentrations of prostaglandins. As a consequence, reduction in inflammation and its accompanying pain, fever, swelling and tenderness. The manufacture of Celecoxib has been described in various patents and to cite a few references, G. D. Searl \& Co. has disclosed method for preparation of Celecoxib [2-3] in US 5,466,823 which is as under: US 5,134,142 [2], US 5,563,165, US 6,150,534, US 5,892,053,
US 2007/0004924, US 2008/0234491, EP 1,528,058, EP 1,167,355, EP 2,246,332, WO 01/42221, WO 03/090730, W005/014546, WO 06/051340, WO 08/145733, and WO 2010/095024 have also described the synthesis of Celecoxib Reddy et al in their publication in Org. Process Res. Dev., 2009, 13(1), pp 98-101. have disclosed the synthesis (Figure 3).

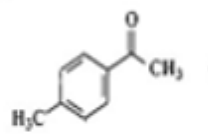

II

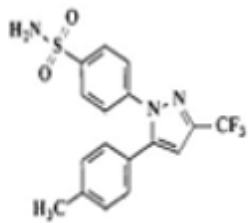

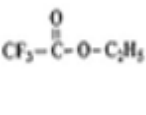

III

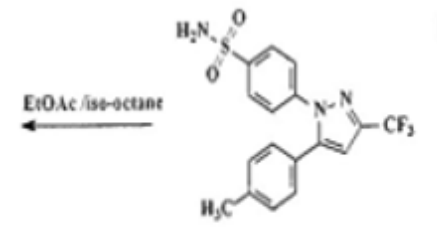

1

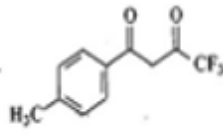

N
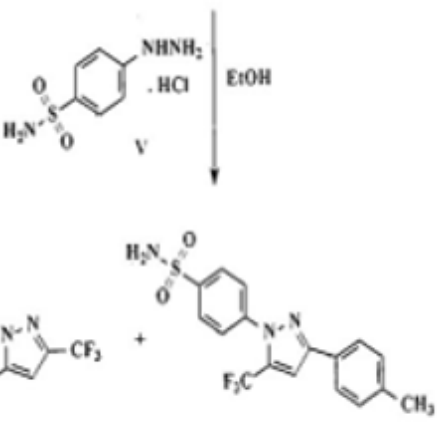

1

Figure 3: Manufacture of Celecoxib.

\section{Detailed Description of the Drawings}

Figure 1 describes the powder X-ray diffraction pattern of the Celecoxib Polymorph; Figure 2 illustrates $2 \theta$ values. Figure 3 depicts the DSC thermogram taken at 10:C /min over a temperature range of 30:C to 200:C for Celecoxib polymorphic form.

\section{Description of the Process}

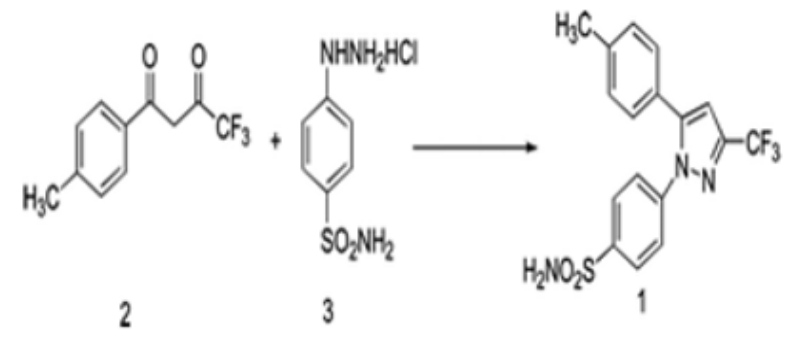

Figure 4: Crystals of Celecoxib polymorph.

The present procedure describes the preparation of Celecoxib by a novel process and its crystallization to polymorphic form. The present process for the preparation of Celecoxib by a process involving condensation of 4,4,4-trifluoro-1-[4-(methyl) phenyl]butane-1,3-dione [1] with sulphonamido phenyl hydrazine hydrochloride [2] in an aqueous medium to give Celecoxib [3]. This is followed by crystallization from a mixture of solvents [48] containing Aromatic hydrocarbon and aliphatic ketone. In the condensation reaction the reactants are added in water and reactions done at ambient temperature. The crude Celecoxib is isolated by filtration. In the for purification of Celecoxib and its crystallization to polymorphic FORM Preparing a solution of Crude Celecoxib in a solvent mixture comprising of an aliphatic ketone (Acetone) and an aromatic hydrocarbon (Toluene)at reflux temperature followed by cooling crystallization to give crystals of Celecoxib polymorph [8-12] (Figure 4).

Table 1:

\begin{tabular}{|c|c|}
\hline Signal & Assignment/Remarks \\
\hline $2.3 \mathrm{ppm}$ & $3 \mathrm{H}$, methyl, Singlet \\
\hline 3.337 and $3.329 \mathrm{ppm}$ & Residual H of DMSO d6, ignore \\
\hline $7.20 \mathrm{ppm}$ & $4 \mathrm{H}$, Aromatics, multiplet \\
\hline $7.53 \mathrm{ppm}$ & $3 \mathrm{H}$, Aromatics, $1 \mathrm{H}, \mathrm{H}-4$ (pyrazole) \\
\hline $8.8 \mathrm{ppm}$ & $1 \mathrm{H}$, Aromatic, doublet \\
\hline
\end{tabular}

In this process by carrying out the final step of condensation in the aqueous medium followed by crystallization, the residual solvents limits are well taken care of. The yields in the process are higher compared to the prior art, which makes it a cost-effective process. Formation of isomers are less compared with the prior art, which makes it effective to make it to the pharmacopoeia grade. Residual solvents play a very important role in the impurity profile of APIs as per the ICH Guidelines ICH Q3C (R4). In this process 
by carrying out the final step of condensation in the aqueous medium followed by crystallization, the residual solvents limits are well taken care of $[13,14]$. The crystallization conditions are well established to give crystalline polymorph. The powder X-Ray diffraction pattern of the Celecoxib is given in Figure 1 and $2 \theta$ values are given in Table 1 of Figure 2. The differential scanning calorimeter graph of the Celecoxib polymorph under specific conditions shows the melting point around $162.7^{\circ} \mathrm{C}$. The DSC of Celecoxib is given in Figures 3,5, and 6.

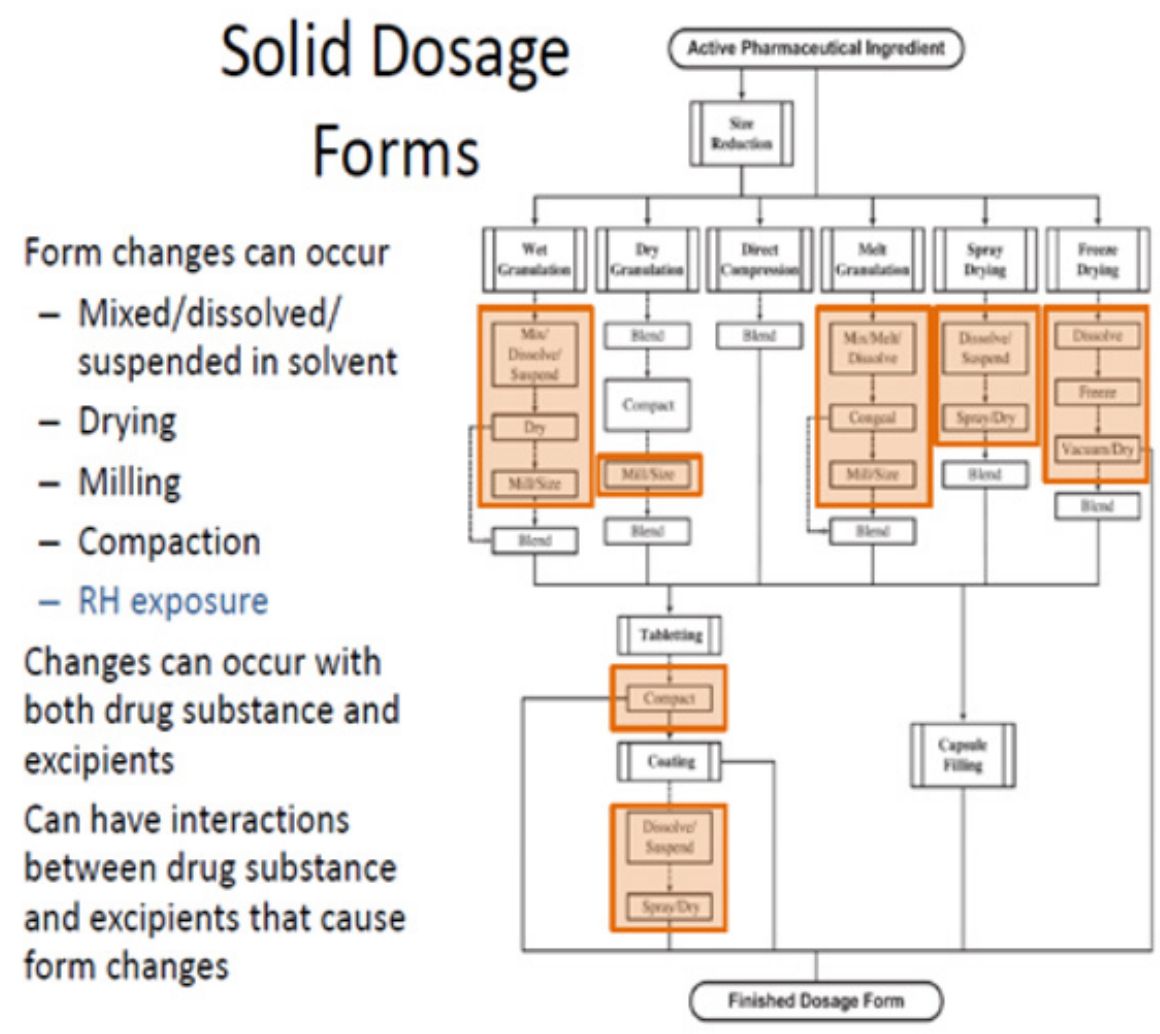

Figure 5: Solid Dosage Forms.

\section{Process Induced Transformations}

- Cá n involve one component or more

- Can be solid-solid or solid-liquid-solid

- Can happen with compound, excipient, or both

\begin{tabular}{|c|c|c|}
\hline Basic prosess & Stave of aggregation & Specific process \\
\hline \multirow{2}{*}{$\begin{array}{l}\text { Trans:formations } \\
\text { (exe compenient) }\end{array}$} & Solid-selad & Polymoeptic trancformations \\
\hline & Solid-liquid-tobid & 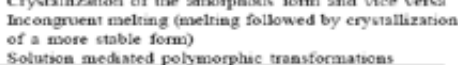 \\
\hline \multirow{3}{*}{$\begin{array}{l}\text { Physucal interactions } \\
\text { (nasulticomponent) }\end{array}$} & Solid-solad & Eutestic reaction \\
\hline & Solid-liquid-solid & $\begin{array}{l}\text { Formation of a molecular compound or a solid solation } \\
\text { (incluating solvate formation) cocrystals, salts }\end{array}$ \\
\hline & $\begin{array}{l}\text { Solid-solid or } \\
\text { Solid-liquiid-solid }\end{array}$ & Hydrate fonmation in humid air \\
\hline $\begin{array}{l}\text { Physeal deconponstions } \\
\text { (multicemiponcat) }\end{array}$ & $\begin{array}{l}\text { Solid-solid or } \\
\text { Solid-lrquad-solid }\end{array}$ & Devolvation dissociation \\
\hline
\end{tabular}

Figure 6: Process induced transformations.

\section{Solid Forms}

a) Propensity to produce different forms not significantly different for salts and non-salts.

b) Need more data on co-crystals (Figure 7).
The details of the new methods for preparation of celecoxib are further illustrated in the following examples.

\section{Example 1: Preparation of Celecoxib}

In a 20 liter 3-necked flask, equipped with stirrer, thermometer 
and reflux condenser, deionized water (7.9 Liter) is charged and mixture of 4,4,4-trifluoro-1-[4-(methyl) phenyl]-butane-1,3-dione (1.6Kg; $6.95 \times 10^{3} \mathrm{mmoles}$ ) and 4 -sulphonamido phenyl hydrazine hydrochloride $\left(1.7 \mathrm{Kg} ; 7.57 \times 10^{3} \mathrm{mmoles}\right)$, a resultant mixture was heated at $75^{\circ} \mathrm{C}$ to $80^{\circ} \mathrm{C}$ and maintained for 5 hours. The reaction mixture was cooled to $25^{\circ} \mathrm{C}$ to $30^{\circ} \mathrm{C}$ to give a slurry. The slurry was filtered and washed with water (3.2liter) wet- cake was collected and further processed for purification as given below.

Table 2. Percentages of Forms from Polymorph Screening

\begin{tabular}{lccc}
\hline & $\begin{array}{c}\text { all } \\
\text { compounds } \\
\text { [count (\%)] }\end{array}$ & $\begin{array}{c}\text { salts } \\
\text { [count (\%)] }\end{array}$ & $\begin{array}{c}\text { non-salts } \\
{[\text { count (\%)] }}\end{array}$ \\
\hline multiple forms $^{a}$ & $220(89)$ & $86(91)$ & $116(91)$ \\
multiple crystalline forms $^{b}$ & $200(82)$ & $77(81)$ & $105(82)$ \\
polymorphs $^{c}$ & $118(48)$ & $37(39)$ & $71(55)$ \\
hydrates $_{\text {solvates }}$ & $94(38)$ & $46(48)$ & $38(30)$ \\
noncrystalline & $78(32)$ & $34(36)$ & $36(28)$ \\
total compounds & $118(48)$ & $51(54)$ & $55(43)$ \\
& 245 & 95 & 128
\end{tabular}

${ }^{a}$ Crystalline polymorphs, hydrates, and solvates plus noncrystalline forms. ${ }^{b}$ Crystalline polymorphs, hydrates, and solvates. ${ }^{C}$ Crystalline polymorphs.

Figure 7: Percentages of forms from Polymorph Screening.

a) Purification and Crystallization to Give Polymorph: Celecoxib wet-cake obtained in the process described above was taken into 20 liter 3-necked flask, equipped with stirrer, thermometer and reflux condenser, mixture of acetone (0.54liter) and toluene (10.8liter) was added and the reaction mixture was heated to $80^{\circ} \mathrm{C}$ to $85^{\circ} \mathrm{C}$ for 30 minutes. Activated carbon $(0.3 \mathrm{Kg})$ was added and the reaction mixture was further heated to $80^{\circ} \mathrm{C}$ to $85^{\circ} \mathrm{C}$. The reaction mixture was cooled to $25^{\circ} \mathrm{C}-30^{\circ} \mathrm{C}$. The slurry was filtered, washed with toluene and then dried at $70^{\circ} \mathrm{C}$ to yield the Celecoxib polymorph compound1.35 kg (HPLC purity-99.8\% \& molar yield; 50.9\%).

IR: $3340,3240,1600,1500,1350,1280,1235,1160,980,910$, $840,800,760,635,560,530 \mathrm{~cm}^{-1}$ (KBr pellet)
Proton NMR: Solvent: DMSO d6, $300 \mathrm{MHz}$.

\section{Example 2: Preparation of Celecoxib}

In a 20liter 3-necked flask, equipped with stirrer, thermometer and reflux condenser, charge deionized water(9Liter) and mixture of 4,4,4-trifluoro-1-[4-(methyl)phenyl]-butane-1,3-dione(1.6Kg; $6.95 \times 10^{3} \mathrm{mmoles}$ ) and 4-sulphonamido phenyl hydrazine hydrochloride( $\left.1.7 \mathrm{Kg} ; 7.57 \times 10^{3} \mathrm{mmoles}\right)$, a resultant mixture was heated at $90^{\circ} \mathrm{C}$ to $100^{\circ} \mathrm{C}$ and maintained for 5 hours. The reaction mixture was cooled to $25^{\circ} \mathrm{C}$ to $30^{\circ} \mathrm{C}$. The slurry was filtered and washed with water (3.2liter) wet-cake was collected and further processed for purification as given below.

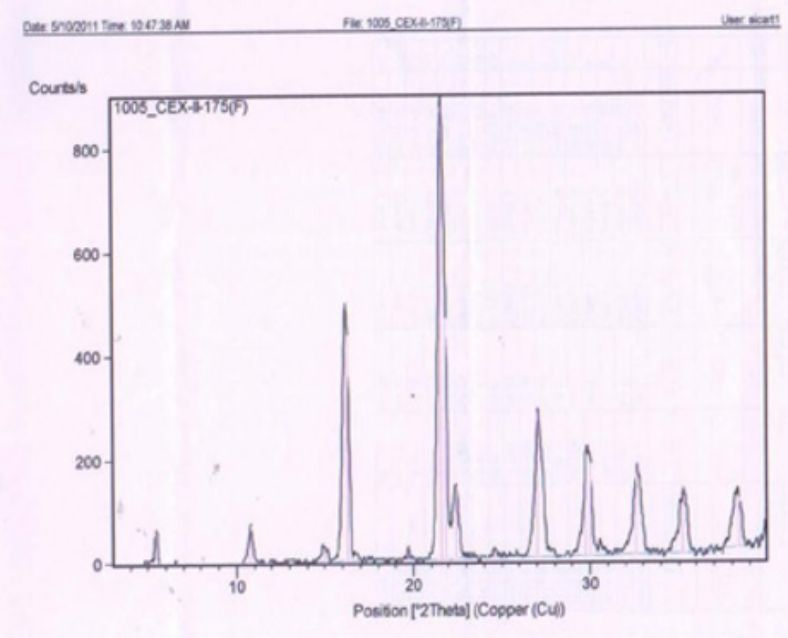

Figure 8: Powder X-Ray diffraction pattern of the Celecoxib. 
a) Purification and crystallization to give Polymorph: Celecoxib wet-cake obtained in the process described above was taken into 20liter 3-necked flask, equipped with stirrer, thermometer and reflux condenser, mixture of acetone (0.54liter) and toluene (10.8liter) was added and the reaction mixture was heated to $80^{\circ} \mathrm{C}$ to $85^{\circ} \mathrm{C}$ for 30 minutes. Activated carbon $(0.3 \mathrm{Kg})$ was added and the reaction mixture was further heated to $80^{\circ} \mathrm{C}$ to $85^{\circ} \mathrm{C}$. The reaction mixture was cooled to $25^{\circ} \mathrm{C}-30^{\circ} \mathrm{C}$. The separated solid was filtered, washed with toluene and then dried at $70^{\circ} \mathrm{C}$ to yield the Celecoxib polymorph compound1.24 kg (HPLC purity-99.3\% \& molar yield; 47\%) (Figures 8-11c).

\begin{tabular}{|c|c|c|c|c|c|c|}
\hline \multicolumn{7}{|c|}{ 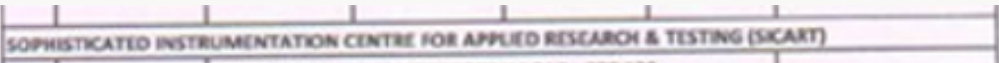 } \\
\hline \multirow[b]{3}{*}{ No. } & \multirow[b]{3}{*}{ Misible } & \multicolumn{4}{|c|}{ 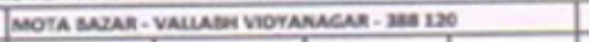 } & \\
\hline & & & & & & \\
\hline & & $\begin{array}{l}\text { Dataset } \\
\text { Name }\end{array}$ & $\begin{array}{l}\text { seart pos. } \\
\text { r2my }\end{array}$ & $\begin{array}{l}\text { End pos } \\
\text { [2]m] }\end{array}$ & $\begin{array}{l}\text { step } \\
\text { remh }\end{array}$ & $\begin{array}{l}\text { Neasured } \\
\text { Date/nime }\end{array}$ \\
\hline & & & & & & \\
\hline 1) & Thue & \begin{tabular}{|l|}
$200 s_{1} C E X-11-$ \\
$175(\eta)$
\end{tabular} & 3.01 & 39.99 & 0.02 & $5 / 10 / 201110228$ \\
\hline & & & & & & \\
\hline No. & Pos. $[2 \mathrm{~m}]$, & d-spacing & Significance & Ret. ine $[\mathbf{X}]$ & Height & FWh:M[2T] \\
\hline & & & & & & \\
\hline 3) & 5.4088 & 1633928 & 3.1357 & 9.86 & 64.67 & 0.1968 \\
\hline 2 & 10.8034 & 2.18943 & 1.1256 & 7.54 & 71.62 & 0.1378 \\
\hline 3 & 13.0126 & 6.80362 & 2.891 & 2 & 5.45 & 0.4723 \\
\hline 4 & 15.0126 & 5.90145 & 1.6412 & 7.38 & 24.2 & 0.3936 \\
\hline s) & 16.2935 & 5.44029 & 9.2472 & 100 & 437.32 & 0.2952 \\
\hline 6 & 19.6596 & 4.50094 & 0.9851 & 204 & 223 & 0.1181 \\
\hline 7 & 21603 & 4.1137 & 1.0274 & 80.09 & 875.58 & 0.1181 \\
\hline 8 & 218734 & 4.06365 & 09792 & 42.77 & 467.65 & 0.1181 \\
\hline 9 & 22.4507 & 2.96026 & 14827 & 21.45 & 140.72 & 0.1968 \\
\hline 10 & 23.824 & 3.735 & 0.8233 & 0.45 & 4.89 & 0.1181 \\
\hline 11 & 24.5936 & 3.61934 & 0.833 & 4.77 & 13.03 & 0,722 \\
\hline 12 & 27.054 & 3.29597 & 0.8743 & 25.62 & 280.08 & 0.1181 \\
\hline 13. & 29.7841 & 2.9997 & 1.0083 & 31.13 & 204.23 & 0.1968 \\
\hline 14 & 30.0469 & 2.97413 & 1.1786 & 19.03 & 178.3 & 0.1378 \\
\hline 15 & 32.6341 & 2.74401 & 16601 & 36.52 & 171.12 & 0.2755 \\
\hline 16 & 35.3029 & 2.51245 & 16827 & 2654 & 12436 & 0.2755 \\
\hline 17 & 38.4104 & 2.34361 & 4.8635 & 40.55 & s5 & ass1 \\
\hline
\end{tabular}

Figure 9: $2 \theta$ values.

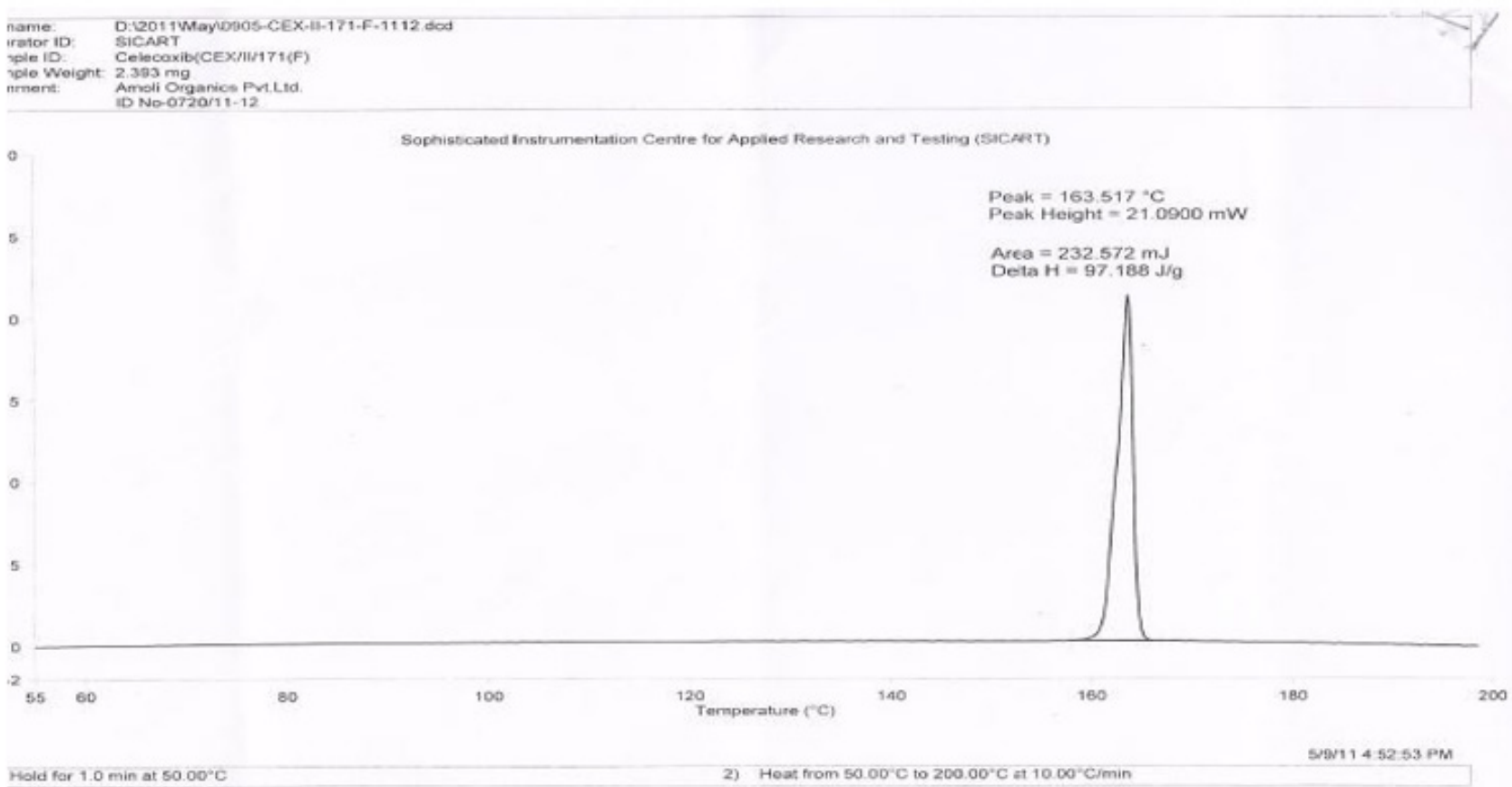

Figure 10: DSC of Celecoxib. 


\section{Suspension}

- Celecoxib

- Three unsolvated forms (I, II III)

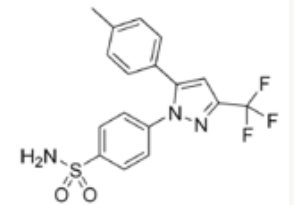

- Form III thermodynamically stable form at RT

- Two solvates: $\mathrm{N}, \mathrm{N}$-dimethyl acetamine and $\mathrm{N}, \mathrm{N}$-dimethyl formamide (DMF)

- Suspension formulation made with Form III

\begin{tabular}{|c|c|c|c|c|c|c|}
\hline \multirow[b]{2}{*}{ Ingredient } & \multicolumn{6}{|c|}{$5 \% \mathrm{wix}$} \\
\hline & Lot A & Lot B & Lot $C$ & Lot D & Lot $E$ & Lot $\mathbf{F}$ \\
\hline Celecoxib & 1.77 & (120) & 177 & 1.77 & & 1.77 \\
\hline HPMC 2910 USP is & 4 & 1 & 5 & 5 & 25 & 5 \\
\hline PEG 400 & 4.13 & 2.9 & & 4.13 & 413 & 4.13 \\
\hline Polysorbate 80 & 1 & $\mathrm{~T}$ & 1 & 1 & 0.5 & 0 \\
\hline $\begin{array}{l}\text { PVP K90 } \\
\text { Sorium bennont }\end{array}$ & $\therefore 2$ & 12 & ${ }_{002}^{0}$ & ${ }_{02}^{2}$ & ${ }_{02}^{1}$ & $a_{02}^{2}$ \\
\hline Citrie acid & 1.31 & $\begin{array}{l}0.2 \\
1.31\end{array}$ & $\begin{array}{l}.2 .2 \\
1.81\end{array}$ & $\begin{array}{l}0.2 \\
1.31\end{array}$ & $\begin{array}{l}0.81 \\
1.31\end{array}$ & $\begin{array}{l}2.2 \\
1.31\end{array}$ \\
\hline Sedium citrate & 1.11 & & & 1.11 & & 1.11 \\
\hline 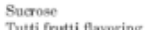 & 30 & 30 & 0 & 30 & 15) & 0 \\
\hline $\begin{array}{l}\text { Tutti fiutti flavoring } \\
\text { DI water. }\end{array}$ & $9 \times$ to 100 & $\begin{array}{c}0 \\
\text { q.x to } 100\end{array}$ & $\begin{array}{l}0.05 \\
\text { q.: to } 100\end{array}$ & $\begin{array}{l}0.05 \\
\text { q.s. to } 100\end{array}$ & $\begin{array}{l}0.08 \\
9 \times 50\end{array}$ & $\begin{array}{l}0.05 \\
x \text { to } 10 x\end{array}$ \\
\hline
\end{tabular}

Figure 11a

\section{Suspension}

XRPD showed Lot B contained a new form of celecoxib (Form IV) Upon heating, Form IV melts and converts to Form III

IPA slurry with Forms III and IV show Form III is more stable at RT
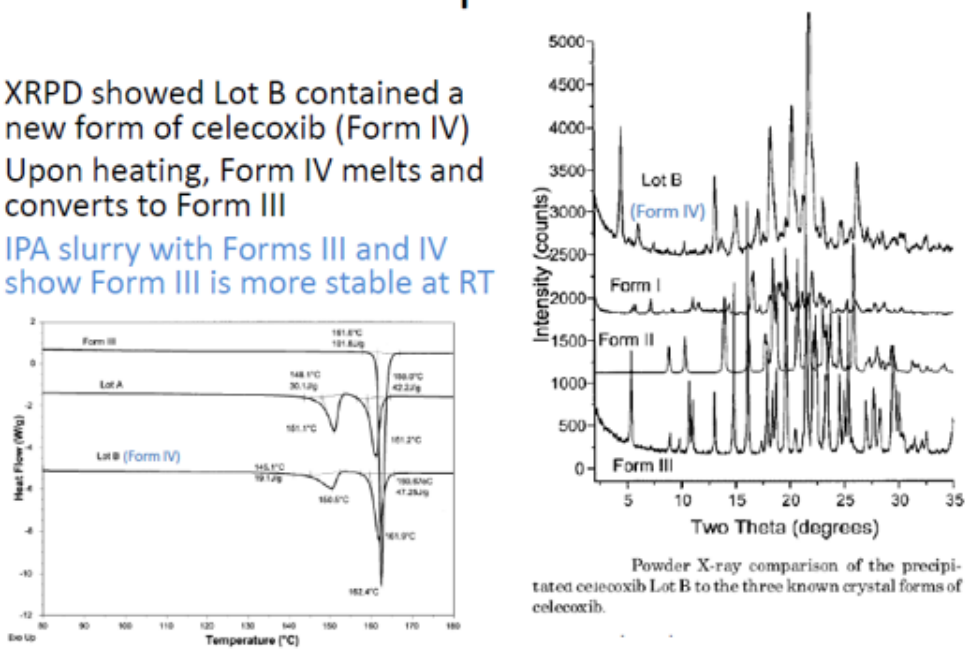

Figure 11b

\section{Suspension}

- Metastable Form IV produced from formulation process

- Found concentrations and ratio of HPMC and Polysorbate 80 were critical to the generation of Form IV

- Form IV is $2-3 \mathrm{X}$ more soluble than Form III

- Formulations with Form IV are stable at $40^{\circ} \mathrm{C}$ for at least 6 months and at $25^{\circ} \mathrm{C}$ for at least 16 months

- Possible to stabilize metastable Form IV in suspension and achieve higher bioavailability

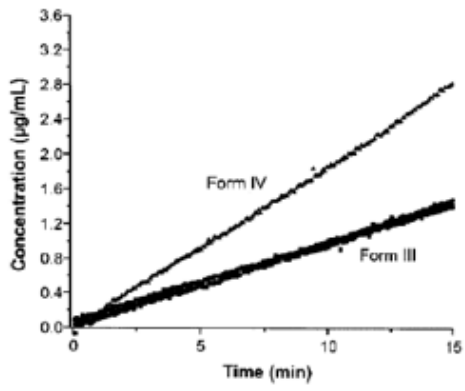

Rotating disk dissolution for Form IV and Form III of celecoxib.

- Processing conditions and excipients can affect form; excipients can stabilize forms

Figure 11c 


\section{Conclusion}

The distinct advantage of the present method of preparation over the prior art can be summarized as per below:

The present process, which describes the manufacturing process of Celecoxib, which is a non- steroidal anti-inflammatory drug (NSAID), has the advantage of scaling up to the industrial level of production. The process uses safe reagents in the process which makes it for industrial scale operations. The present process provides an improved process for the preparation of 4-[5-(4-methylphenyl)-3- (trifluoromethyl)-1H-pyrazol-1yl] benzene sulfonamide (Celecoxib) and its purification and crystallization to produce polymorph. The yields in the process are high compared to existing process which makes it a cost-effective process. Formation of isomers are less compared with the prior art, which makes it effective to make it to the pharmacopoeia grade. In this process by carrying out the final step of condensation in the aqueous medium followed by crystallization, the residual solvents limits are well taken care of. The yields in the process are higher compared to the prior art, which makes it a cost-effective process. Residual solvents play a very important role in the impurity profile of APIs as per the ICH Guidelines ICH Q3C (R4).

\section{References}

1. Pouton CW (2006) Formulation of poorly water-soluble drugs for oral administration: physicochemical and physiological issues and the lipid formulation classification system. Eur J Pharm Sci 29(3-4): 278-287.

2. Matsuo (2012) US 5,134,142, US 5,563,165, US 6,150,534, US5,892,053, US $2007 / 0004924$.
3. G Sievers R (Eds.); Data Commission of the International Union of Crystallography, Bonn pp. 171-200.

4. Anonymous (2001) 50 top selling drugs ranked by worldwide sales for 2000, Patent scan-a monthly proactive patents bulletin for pharmaceutical industry. Med Ad News 2(12).

5. Behme RJ, Brooke D, Farney RF, Kensler TT (1985) Characterization of polymorphism of gepirone hydrochloride. J Pharm Sci 74(10): 10411046.

6. Brittain HG (1997) Spectral methods for the characterization of polymorphs and solvates. J Pharm Sci 86(4): 405-412.

7. Brittain H, Fiese E (1999) Effects of pharmaceutical processing on drug polymorphs and solvates. In: Swarbrick J (Eds.); Polymorphism in Pharmaceutical Solids. Marcel Dekker, New York, pp. 331-365.

8. Brittain HG and Grant DJW (1999) Effects of polymorphism and solidstate solvation on solubility and dissolution rate. In: Swarbrick J (Eds.); Polymorphism in Pharmaceutical Solids. Marcel Dekker, New York pp. 279-330.

9. Giron D (1995) Thermal analysis and calorimetric methods in the characterization of polymorphs and solvates. Thermochim Acta 248: $1-59$.

10. Halgren T (1990) MOMEC force field parameters. J Am Chem Soc 112: 4710-4725.

11. Hancock B, Zografi G (1997) Characterization and significance of the amorphous state in pharmaceutical systems. J Pharm Sci 86(1): 1-12.

12. Jozwiakowski M (2000) Alteration of the solid state of the drug substance: polymorphs, solvates, and amorphous forms. In: Liu R (Eds.); Water Insoluble Drug Formulation. Interpharm Press, Colorado pp. 525562 .

13. Kakumanu V, Bansal A (2002) Enthalpy relaxation studies of celecoxib amorphous mixtures. Pharm Res 19(12): 1873-1878.

14. Leonard F, Patricia M (1999) Polymorphic crystalline forms of celecoxib.

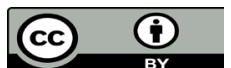

This work is licensed under Creative Commons Attribution 4.0 License

To Submit Your Article Click Here:

Submit Article

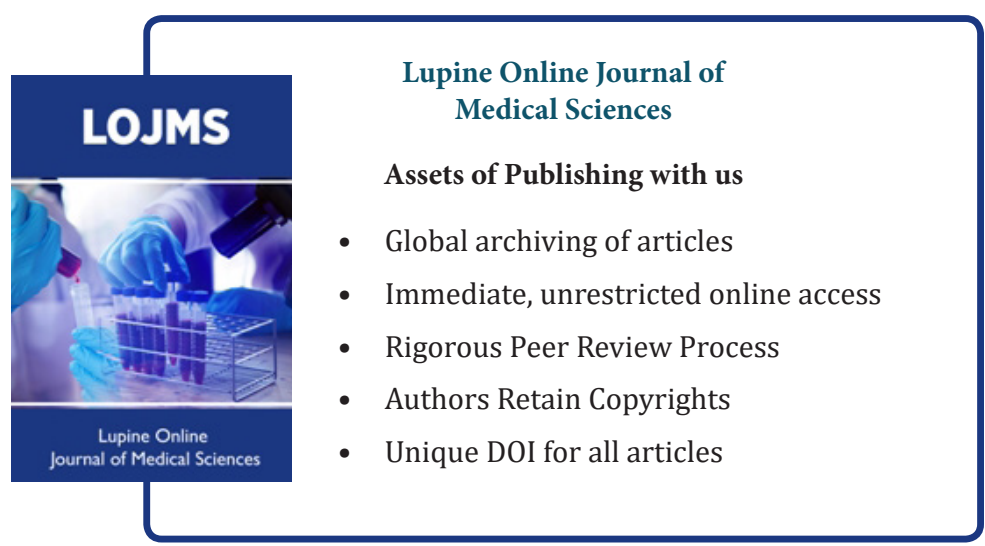

